\title{
20 anos do curso de Letras/Espanhol da UFG: um sonho do Prof. Fernando Plaza
}

\author{
Cleidimar Aparecida Mendonça e Silva*
}

\begin{abstract}
Él tiene los ojos buenos y una figura pesada la edad se le vino encima sin carnaval ni comparsa yo tengo los años nuevos y el hombre los años viejos el dolor lo lleva adentro.

Piero
\end{abstract}

\begin{abstract}
Resumo
Este artigo presta uma homenagem ao professor chileno, Fernando Plaza Mallea, idealizador da licenciatura em Letras: Espanhol da Universidade Federal de Goiás, por ocasião dos 20 anos de colação de grau da primeira turmaa graduar-se nessa modalidade. O referido docente ministrou as disciplinas de latim e espanhol tanto no antigo ICHL (Instituto de Ciências Humanas e Letras) quanto na atual Faculdade de Letras da Universidade Federal de Goiás. O Prof. Plaza vislumbrou a possibilidade de uma licenciatura em Espanhol em Goiás a partir da criação do Mercosul, Mercado Comum do Sul, em 1991 (acordo de livre comércio e união aduaneira) entre Brasil, Argentina, Paraguai e Uruguai e também pelo fato de o Brasil estar rodeado de países de língua espanhola no continente sul-americano. Em 1996, quando o nosso mestre se aposentou, já tinha visto seu sonho, mesmo que parcialmente, transformar-se em realidade. A graduação em Letras: Espanhol habilitou, de 1998 a 2018, 268 profissionais docentes, segundo informação da Coordenadoria de Expedição e Registro de Diplomas da UFG. Esses egressos tiveram acesso a processos seletivos e concursos públicos, podendo exercer sua profissão em instituições de ensino infantil, básico, técnico, tecnológico e em faculdades. Em 2004, o Prof. Plaza faleceu e não pôde acompanhar o retorno à própria UFG de muitos ex-alunos que passaram a atuar como professores efetivos no curso de licenciatura em Espanhol no qual se formaram.
\end{abstract}

Palavras-chave: homenagem, prof. Fernando Plaza, licenciatura em Espanhol, 20 anos, egressos.

\section{0 years of Spanish Language Teaching Programme at UFG: a history born out of Professor Fernando Plaza's dream}

\begin{abstract}
This article pays tribute to a Chilean professor, Fernando Plaza Mallea, who idealized and initiated the Spanish Language Teaching Programme at UFG, currently celebrating 20 years since the graduation of the first group. He taught Latin and Spanish at the former ICHL and at what we know today as the College of Letters, at the Federal University of Goias. Professor Plaza saw the possibility of a Spanish Teaching Education Programme after the creation of Mercosul, the South Common Market, in 1991, a partnership on free trade and customs between Brazil, Argentina, Paraguay and Uruguay; and also due to the fact that Brazil is surrounded by Spanish-speaking countries in South America. When professor Plaza retired in 1996, he could see his dream, though partially, fulfilled. According to the UFG Department of Registration and Diplomas, from 1998 to 2018, the Spanish Language Teaching Programme contributed to the education of 268 teachers. Many of these alumni have so far applied for different teaching selections and have taught in different levels (primary and secondary schools, technology institutions, and colleges). After being able to also witness some of his former students working as professors at the UFG Spanish Language Teaching Programme, professor Plaza died in 2004.
\end{abstract}

Keywords: tribute, professor Fernando Plaza, Spanish Language Programme, 20 years, alumni.

\footnotetext{
* Professora efetiva da UFG, lotada na Faculdade de Letras, nível Adjunto. E-mail: cleidimar@ufg.br.
} 


\section{Introdução}

A licenciatura dupla em Letras (habilitação em Português e Espanhol) foi criada, na Universidade Federal de Goiás (UFG), graças à persistência, coragem e determinação do saudoso mestre Fernando Plaza Mallea, um hispanista chileno. Ao usar o termo "hispanista", baseio-me na definição de Mario González (2005): um pesquisador que, estando fora de seu país de origem, estuda as culturas das nações de língua espanhola. O Prof. Plaza ingressou na UFG em 1965, ministrando as disciplinas de latim e espanhol. Esta era eletiva para cursos nas áreas de medicina, biológicas eexatas e para as turmas de Letras Neolatinas (Português e Francês) do Departamento de Letras do antigo Instituto de Ciências Humanas e Letras (ICHL).

Para tais licenciaturas, o espanhol era Língua Dois (L2), terminologia usada na época, e, juntamente com o italiano, podia ser cursada por alunos desses cursos. Nesse cenário, as turmas de espanhol eram muito grandes, mas o Prof. Plaza, extrovertido e espontâneo, era um docente que se relacionava muito bem com os alunos. Sua atuação, em nosso Estado, também foi bastante relevante. Em 1990, fundou a Associação de Professores de Espanhol do Estado de Goiás (ASPROEGO) e foi o seu primeiro presidente.

Quanto à sua postura, é-me gratificante reconhecer, grata e orgulhosa, como sua ex-aluna, que o Prof. Plaza foi, antes de tudo, um homem apaixonado por sua língua e pelas culturas hispânicas e, com isso, pôde vislumbrar a importância que o espanhol adquiriria nos contextos educativo e laboral no Brasil. Dessa forma, antecipou a demanda que se criaria para a formação de professores de Espanhol como Língua Estrangeira (E/LE). Entretanto, a década de 1990do século XX foi marcada pela ausência de concursos públicos nas Instituições de Ensino Superior públicas e as vagas dos aposentados retornavam, unicamente, para a sua própria área de atuação. Dessa maneira, criar uma nova licenciatura, como a habilitação dupla em Letras (Português e Espanhol), que na época não contava com nenhum profissional especializado para dedicar-se ao espanhol, uma vez que o Prof. Plaza ministrava, prioritariamente, aulas de latim, era um imenso desafio.

Contudo, a voz de nosso hispanista encontrou eco na proposta de mudança das licenciaturas que estava sendo gestada, e amplamente discutida, na Faculdade de Letras (FL) da UFG. Esse fato permitiu a separação das licenciaturas em Português, Inglês, 
Francês e Espanhol, dos cursos de bacharelado em Literatura e bacharelado em Linguística. Dessa forma, em 1992, foi criado o curso de Letras, habilitação dupla em Português e Espanhol, regime anual com a duração de 05 anos que teve a primeira turma de ingressantes em 1994 (da qual orgulhosamente faço parte). Por dois anos, o Prof. Plaza ministrou aulas de latim para o nosso grupo, que enfrentou, como alguns de seus grandes desafios: a falta de professores para atuar no curso, a escassez de materiais didáticos e a inexistência de escolas com aulas de espanhol para realização do estágio.

Em 1996, quando o nosso mestre se aposentou, já tinha visto seu sonho, mesmo que parcialmente, transformar-se em realidade, pois a graduação em Letras (Português e Espanhol) habilitou, de 1998 a 2018, 268 profissionais docentes, segundo informação da Coordenadoria de Expedição e Registro de Diplomas da UFG. Esses egressos tiveram amplo e irrestrito acesso a concursos públicos, bem como ao exercício da profissão em instituições de ensino básico, técnico, tecnológico e em faculdades, com apresentação do diploma nas duas línguas. Em 2004, o Prof. Plaza faleceu e não acompanhou o retorno à casa de muitos ex-alunos que passaram a atuar como professores efetivos na própria FL, no curso de licenciatura em Espanhol no qual se graduaram. Anteriormente, porém, atuaram como substitutos (com contrato temporário) e muitos desses docentes foram imprescindíveis para a formação de novos professores de Espanhol em Goiás. Atualmente, compõem o quadro de docentes efetivos do curso de Letras e Espanhol da FL/UFG três egressas do curso.

Outra questão relevante foi o número expressivo de licenciados em Letras: Espanhol que fizeram opção pela Pós-Graduação stricto sensu e ingressaram em cursos de mestrado e doutorado. Nesse cenário, a Profa. Zaira Turchi, docente aposentada da FL/UFG, presidente da Fundação de Amparo à Pesquisa do Estado de Goiás (FAPEG) e também presidente do Conselho Nacional das Fundações Estaduais de Amparo à Pesquisa (Confap), destacou, por ocasião da escrita de minha tese doutoral, em 2009, que a licenciatura em Espanhol é a segunda graduação que mais forma profissionais, na FL, depois da licenciatura em Inglês. Também ratificou a importância desse curso na diminuição da hegemonia dessa língua anglo-saxã, opinião também corroborada por Cox (2008, p. 3) quando considera que o Mercosul “"...] nos despertou para o estudo do espanhol, relativizando a hegemonia do inglês que, sob o signo do imperialismo 
americano, reinava quase absoluto no ensino regular público e privado e nos cursos livres de idiomas".

Em 2014, o curso de Letras: Espanhol da UFG completou 20 anos de criação e, em abril de 2019, a primeira turma completará 20 anos de sua colação de grau. Como sua integrante, não podia deixar de prestar esta homenagem ao mestre Fernando Plaza, o idealizador de tudo isso. E, para fazê-lo, solicitei alguns depoimentos a professores, técnico-administrativos e ex-alunos que o conheceram e conviveram com ele. Segundo o Dicionário Eletrônico Aurélio, um depoimento é um

\begin{abstract}
ato de depor em juízo, pelo qual uma pessoa, denominada testemunha, faz suas declarações perante a autoridade que a convocou ex officio ou em atenção a pedido deferido por ela. [...] O depoimento, na técnica jurídica, é o meio de prova. A testemunha, ou depoente, alude, em seu depoimento, aos fatos trazidos ao conhecimento do julgador da causa, e assim se insere como elemento fundamental do processo em andamento.
\end{abstract}

Os depoimentos que solicitei possuem um caráter acadêmico e, das definições anteriores, interessam-me as ideias de fazer declarações, aludir a fatos ocorridos, inserirse no processo. Assim, as pessoas que aceitaram falar sobre o Prof. Plaza o fizeram de forma espontânea, ou seja, sentiram vontade de fazê-lo, de dizer algo a respeito do homem visionário, simples e muito solidário que era. Alguém que, sozinho, teve argumentos plausíveis a ponto de convencer os colegas a criar uma licenciatura em uma língua que não contava com nenhum profissional de Espanhol concursado, além dele próprio, naquela época.

\title{
Depoimentos: o resgate de algumas memórias
}

Os depoimentos foram coletados pore-mail e também foram obtidos por meio de entrevistas gravadas ou registradas por escrito. O primeiro que enviou o seu testemunho foi o Prof. Agostinho Potenciano de Souza, que fez alusão à canção "Mi querido viejo", do cantor ítalo-argentino, Piero, para expressar as recordações que tinha de seu colega Fernando Plaza.

P.S. Mi querido viejo

Trazer do tempo a figura, a imagem que a mente desenha, o que ficou como significado, do Plaza, como o chamávamos, de maneira familiar, como soía acontecer, é como vê-lo sempre se ocupando com os dois pesos que lhe arcavam os ombros, sem deixar de dar-lhe o brilho de um deus andino, lento 
(camina lento, ¡viejo, mi querido viejo!) e firme nos passos para a frente. Num dos ombros pesava o antigo latim e o seu destino de quase não-lugar nos cursos de letras; no outro, o espanhol como licenciatura, não mais justificada pela cultura irmã nas origens e na literatura, mas embalado pelos horizontes econômicos do Mercosul, na segunda metade da década de 1990. Quase duas décadas depois, é justo destacar a força que seu empenho representa: o latim permanece e tem seu brilho próprio; o espanhol, bem percebido por ele em sua hora e vez, torna-se uma licenciatura de grande sucesso. Além disso, a luz de um professor que estava muito próximo dos alunos, na sala de aula, no gabinete, nos corredores, suave, aplicado, constante, é um signo do valor que pode ter quem, neste lugar, faz o bom movimento da nossa história.

[Agostinho Potencianode Souza]

Em seguida, recebemos o depoimento do docente da PUC-GO, o Prof. Giuseppe Bertazzo, também colega do Prof. Plaza, no antigo ICHL, que, gentilmente, aceitou dizer algumas carinhosas palavras sobre o nosso mestre:

Lembro como ele procurava facilitar a convivência e era generoso em emprestar subsídios. O que se poderia dizer, um "amigão". Outros poderão confirmar e, mais ainda, trazer recordações que, sem dúvida, serão mais do que positivas. Com um abraço.

[G. Bertazzo]

Logo depois, o ex-diretor da Faculdade de Letras, o Prof. Francisco José Quaresma de Figueiredo, atual diretor de Relações Internacionais da UFG, informandonos que o Prof. Plaza foi o pioneiro na criação do Centro de Línguas da UFG:

Lembro-me do Prof. Plaza sempre muito bem-humorado e colaborativo. Com sua experiência, auxiliou muito nas discussões acerca da criação do Centro de Línguas. Foi heroico por ter sido, por muitos anos, o único professor da área de espanhol da Faculdade de Letras. Lutou muito pela expansão e consolidação da área, o que ocasionou a criação da Licenciatura em Espanhol. A ele, todo o meu respeito e minha admiração.

[Francisco José Quaresma de Figueiredo]

No depoimento a seguir, da Profa. Margareth Nunes, da área de italiano da FL, vem à tona a figura de um mestre solícito, que nos faz lembrar também a do expoente educador Paulo Freire, por fazer alusão a uma pedagogia que considera a vida, a realidade, isto é, que promove uma reflexão sobre a prática cotidiana. Naquela época, ainda não havia tantas cobranças para afiliar-se a teorias e publicar resultados de pesquisas em periódicos Qualis A, como pondera a Profa. Margareth Nunes. 
Conheci o prof. Fernando Plaza quando ingressei no Curso de Letras em 1978. Nunca me matriculei em suas matérias. Ele estava sempre envolvido com disciplinas eletivas ou extracurriculares, dentre elas o espanhol. Sua alegria, simpatia e um humor peculiar que sempre nos surpreendia e, às vezes, não entendíamos, eram a sua marca registrada. Os problemas de transporte já existiam naquela época (talvez fossem até piores), mas ele estava sempre com a porta do carro aberta para quem quisesse se "espremer" para chegar a tempo às aulas no Campus Samambaia. Lembro-me como se fosse hoje de seu abraço quando soube de minha aprovação no concurso para professora de italiano da Faculdade de Letras. Guardarei na memória e no coração o seu jeito despojado e bon vivant de conduzir a vida. Foi um professor do grupo que seguia uma pedagogia de reflexão sobre a vida, sobre o quotidiano, sobre a política sem colocar qualquer teoria como escudo.

[Margareth Nunes]

Nos depoimentos dos técnico-administrativos, na sequência, fica o registro do homem bom, democrático, justo, solidário e cumpridor de seus deveres acadêmicos, alguém que não os via de forma assimétrica, mas os tratava e os respeitava como iguais.

Ele sempre foi bom, amigo dos servidores da secretaria do ICHL. O vínculo era de colegas de repartição. Ele era um colega nosso. Ajudava financeiramente as pessoas, o pessoal da limpeza, por exemplo, que naquela época não era terceirizado.

Era amigo também do pessoal da limpeza. Era uma pessoa muito humilde, muito humana.

[Carmina Gonçalves Mota e Souza]

O que me vem à mente a respeito do Prof. Fernando Plaza é a sua dedicação à Faculdade de Letras, a sua humildade, tanto com os servidoresadministrativos, os professores, quanto com os funcionários da limpeza. Muito dedicado, ajudava... Se ele soubesse de alguém que estava até em condição financeira ruim, ele contribuía com dinheiro porque ele tinha um poder aquisitivo melhor, [...] era delegado e professor, ele era uma pessoa que ajudava muito o próximo. Era uma pessoa tranquila, cumpridora de seus deveres. Eu que sempre trabalhei na área administrativa e trabalhei com frequência, com notas também, nunca vi ninguém reclamar que ele não tivesse entregado notas, que ele tivesse faltado ao trabalho. Era um exemplo de profissional. Uma calma muito grande, transmitia muita paz e sempre de bom humor. [...] Para ele não tinha diferença ele ser professor e nós servidores. Sempre ali, amigo de todo mundo, sempre rindo. Eu não fui aluna dele, não o conheci como professor, mas como colega. Então o que eu tenho a dizer é isso, que ele foi uma pessoa que marcou, que passou e deixou uma marca na Faculdade de Letras.

[Vera Lúcia Roncato]

O que eu tenho a dizer sobre o Prof. Fernando Plaza é que ele era uma pessoa muito amiga, muito companheira, um profissional competente. Uma pessoa, digamos assim, que batalhou bastante pela criação do Curso de Espanhol e era uma pessoa que não media esforços para atender os alunos. Uma pessoa sempre solícita, uma pessoa sempre disposta a atender os alunos, uma pessoa sempre aberta a fazer esse atendimento. Tinha um relacionamento muito bom com todos, uma pessoa amigável. Uma pessoa assim que vivia uma vida, de certa forma, bastante tranquila. Parecia ser uma pessoa bastante calma, 
tranquila e que tinha essa empatia com todos e principalmente com os alunos. Eu presenciei várias vezes ele atendendo aluno no corredor, na sala de café, no gabinete dele, sempre tinha aluno lá conversando com ele. Qualquer dúvida ele estava sempre disposto a ajudar. Então, em minha opinião, era um profissional competente, sempre disposto a sanar as dúvidas dos alunos. Ele tinha essa disponibilidade.

Na minha concepção, ele realmente era um professor por vocação, ele fazia aquilo com amor, com dedicação.

[Rodrigo Damásio Lima]

Quanto aos alunos, faltaria espaço, neste texto, para que pudessem expressar as suas opiniões, a sua gratidão e o seu reconhecimento ao incansável trabalho prestado pelo Prof. Plaza e pelo legado que deixou à licenciatura em Letras: Espanhol. Por isso, apenas duas ex-alunas de nosso curso, egressas de 1998, deram seu depoimento em nome das demais colegas. A primeira a falar foi Dormelina da Silva Pires, professora efetiva da Secretaria Municipal de Educação de Goiânia, e também docente no "Projeto Línguas LTDA”.

[...] O que posso dizer é que ele estava sempre sereno, tranquilo, alegre, de peito aberto, sorriso franco. Tinha um prazer enorme em ensinar. Suas aulas eram bastante descontraídas. Gostava muito de ajudar a quem precisava. Demonstrava ser uma pessoa muito humilde e simples. Eu sei que se o curso existe hoje isso se deve a ele. [...] Acho que [...] ele tenha visto uma oportunidade para difundir a cultura hispânica (que era a sua). Talvez por idealismo, ou talvez tenha encontrado em nós (alunos de português) a arma certa para romper as barreiras do "preconceito" do menosprezo a uma língua e cultura tão rica, variada. Se ele vislumbrava a importância que o espanhol adquiriu hoje (ainda precisa melhorar) eu não sei. O que sei é que o espanhol tem a importância que tem hoje, em Goiânia, por causa do seu grandioso gesto. Como posso avaliar o papel dessa licenciatura? Como fundamental, essencial, importantíssimo... Saí da primeira turma, fui cobaia, fui criticada por uns, apoiadíssima por outros, mas a prova de que tudo valeu a pena, de que a licenciatura deu certo, de que a luta não foi em vão sou eu: saí da universidade direto para a escola municipal (em 1999). Nunca fiquei um dia desempregada. Já trabalhei em quatro escolas diferentes e nunca dei uma aula de português. Só não estou rica, porque professor não fica mesmo. Não somos valorizados e isso todos sabem, mas faço o que gosto: ensino algo que já faz parte da minha alma. Repito "Tudo vale a pena se a alma não é pequena". Ele deixou sua terra natal, chegou aqui, se naturalizou brasileiro, mas sua alma era chilena. E com essa alma hispânica ensinou, não só a língua, mas também a lutar e sua luta não foi em vão. Tudo valeu a pena. Tenho certeza de que, se ainda estivesse aqui, faria tudo de novo, se fosse preciso.

[Dormelina da Silva Pires]

A seguir, a ex-aluna Mariana de Souza Garcia, atualmente professora efetiva na Universidade Federal do Mato Grosso do Sul (UFMS), Campus de Três Lagoas, 
endossou as qualidades e o pioneirismo do Prof. Plaza na implantação do curso de Letras: Espanhol.

[...] Foi pioneiro na implantação da habilitação Português/Espanholna UFG. [...] Mostrava ser um grande conhecedor do Latim. Era responsável, assíduo, nas suas aulas, e as ministrava de modo descontraído, simples, mas demostrando um grande conhecimento do tema. Foi nosso professor de Latim e de Língua Espanhola. Deixou-nos suas marcas, uma boa impressão. Foi com ele que obtive as noções sobre os casos e declinações do Latim, temas básicos para depois compreender a Filologia Românica, disciplina que muito apreciei. Se não me engano, foi a primeira pessoa que ouvi pessoalmente, falando espanhol, levei um choque de início, mas algumas aulas depois já me familiarizava com a língua que era apresentada de um modo que propiciava mais a sua aquisição do que seu aprendizado, o que considero muito bom, sobretudo no primeiro contato com uma língua estrangeira. Recordo-me também que foi nosso homenageado na colação de grau e que presenteou a cada uma de nós com um pingente de meio coração contendo uma frase latina ou em língua espanhola [Tú y yo siempre juntos]. Tenho o meu ainda comigo [...].

[Mariana de Souza Garcia]

\section{Registro escrito: um livro cheio de memórias sobre a FL}

Buscando registros sobre a atuação do Prof. Plaza, vale a pena destacar o livro publicado pela Profa. Vera Maria Tietzmann Silva, 50 anos de Letras na UFG: um projeto em construção - memória e história, lançado em 2012, por ocasião do centenário da FL, pela Cânone Editorial. No trecho a seguir, a autora mostra como novos cursos surgiram no antigo ICHL, na década de 1990, entre eles a licenciatura em Espanhol. Destaca, também, a atuação do Prof. Fernando Plaza nessa empreitada:

[...] Ainda nessa mesma década, entraram em funcionamento em 1995 o Centro de Línguas e a licenciatura em Espanhol, esta já aprovada desde fins de 1993. Essas novas ofertas tiveram resposta favorável do público-alvo e, em pouco tempo, o novo prédio [o ICHL 3 foi destinado só para o curso de Letras] começou a mostrar-se pequeno para a enorme demanda que passou a ter. A licenciatura em Espanhol era uma antiga aspiração do Departamento de Letras. Ao tempo da instalação das primeiras turmas da Faculdade de Filosofia da UFG, em 1962, o currículo mínimo determinado pelo MEC já não previa mais as habilitações Neolatinas, Anglo-Germânicas e Letras Clássicas para os cursos de graduação. Ainda assim, desde os primórdios do curso, o Espanhol fazia parte da grade curricular, ao lado de outras línguas estrangeiras, como o Italiano e o Alemão, oferecidas como opcionais, em cursos de três anos, aos alunos das habilitações em Letras Vernáculas ou Letras Modernas (Inglês e Francês), estendendo-se depois sua oferta aos alunos de outras unidades. Contudo, permaneceu latente o desejo de retomar o estudo dessas línguas e suas literaturas com maior profundidade, o que só seria possível abrindo-se uma habilitação específica. Com a assinatura do Tratado de Assunção em 1991, Argentina, Brasil, Paraguai e Uruguai uniram-se para criar uma zona de livre-comércio entre si, o Mercado Comum 
do Sul (Mercosul). Esse evento mobilizou o noticiário econômico internacional na época. Na UFG e também em outras universidades brasileiras renasceu o desejo de se retomar o ensino do Espanhol em bases mais sólidas, abrindo cursos de licenciatura desse idioma nas Faculdades de Letras. Seria uma forma de aproximar também em bases culturais esses países que se propunham ser parceiros econômicos. $O$ chileno Fernando Plaza, professor desde a fundação do curso nos anos 60, foi o grande incentivador da criação da licenciatura em Espanhol. Também pesou consideravelmente a perspectiva da sua reintrodução nos currículos do ensino fundamental e médio como alternativa de língua estrangeira ao lado do Inglês. Aliás, sem essa possibilidade de abertura de mercado de trabalho para os alunos teria sido até temerário criar uma habilitação que formasse docentes dessa língua. Já era suficiente o encolhimento do mercado de trabalho que a Licenciatura em Francês vinha enfrentando fazia alguns anos. Aprovada, a licenciatura em Espanhol teve seu primeiro vestibular em 1994, apresentando boa demanda. Como as habilitações em Francês e Inglês, essa era uma licenciatura dupla, os alunos também se formavam em Português, o que ampliava suas possibilidades de atuação no mercado. Com a duração de cinco anos, essas três habilitações tinham um núcleo comum, além da formação específica em língua e literatura. [...] A conclusão da primeira turma dessa habilitação em 1999 coincidiu com a realização do concurso para admissão de professores de Espanhol da Secretaria Municipal de Educação de Goiânia. Todos os alunos do quinto ano se inscreveram e todos foram aprovados e classificados nos primeiros lugares, o que foi motivo de grande orgulho para toda a Faculdade. O diploma era condição indispensável para que fossem nomeados no cargo. Isso motivou a antecipação da última avaliação parcial, da conclusão do estágio, do registro de notas e da cerimônia de colação de grau, autorizada em caráter excepcional pela Reitoria e realizada no auditório da própria Faculdade de Letras [...] (TIETZMANN, 2012, p. 154-155, grifo meu).

\section{À guisa de conclusão}

Para finalizar, quero destacar que todos os depoimentos corroboram a figura humana bondosa, simples e humilde do Prof. Fernando Plaza, mas, sobretudo, nossos registros destacam a determinação e a ousadia do mestre chileno. Foi, sem dúvida, graças a ele, que a licenciatura em Espanhol foi criada, fomentandoa pluralidade linguística e cultural na UFG, em Goiás e no Centro-Oeste. Por isso, em nome da memória do Prof. Plaza, da história de luta e resistência que procuramos mostrar, neste texto, das turmas de Espanhol formadas e das que ainda se formarão, a reivindicação pela permanência do Espanhol como segunda língua estrangeira de oferta obrigatória, ao lado do inglês, no ensino médio.

\section{Referências}

COX, M. I. P. A hora e a vez do espanhol. Disponível em http://www.ufmt.br/revista/arquivo/rev10/a_hora_e_a_vez_do_espanhol.html. Acesso em 11 fev. 2018. 
196 Polyphonía, v. 30/1, jan./jun. 2019

DICIONÁRIO ELETRÔNICO AURÉLIO. Disponível em http://www.dicionariodoaurelio.com/Depoimento.html. Acesso em 23 set. 2018.

GONZÁLEZ, M. Hispanidad e hispanismo para profesores brasileños de español. In: XI Congreso Brasileño de Profesores de Español. Actas del XI Congreso Brasileño de Profesores de Español. Salvador da Bahia: APEEBA, 2005, p. 2-8.

PIERO. Mi querido viejo. Disponível emhttp://www.musica.com/letras.asp?letra=894397. Acesso em02 nov. 2018.

TIETZMANN, V. M. 50 anos de Letras na UFG: um projeto em construção - memória e história. Goiânia: Cânone Editorial, 2012.

\section{Apêndices}

Perguntas utilizadas na entrevista sobre a trajetória do Prof. Fernando Plaza na FL/UFG:

1. Como você caracterizaria o Prof. Fernando Plaza? Como foi a atuação profissional dele no antigo Instituto de Ciências Humanas e Letras (ICHL) da UFG?

2. A criação do curso de licenciatura em Letras (habilitação em Português/Espanhol) da UFG deve-se à incansável luta do Prof. Plaza. Você se lembra de como tudo aconteceu? Que pessoas e órgãos o apoiaram nessa empreitada? Como a ideia se concretizou na prática? Quais foram as principais dificuldades por ele enfrentadas?

3. Você acredita que o Prof. Plaza já vislumbrava a importância que o espanhol adquiriria no ensino regular brasileiro ou a sua luta era por idealismo (amor à sua língua-cultura maternas)?

4. No ano de 2013, a primeira turma de egressos em Letras (Português/Espanhol) completou 15 anos. Como você avalia o papel dessa licenciatura para a FL/UFG?

5. O que você gostaria de dizer sobre o Prof. Plaza para encerrar o seu depoimento?

Recebido em: 29 mar. 2019.

Aceito em: 26 abr. 2019. 